Columbia Law School

Scholarship Archive

\title{
Prevailing Academic View on Compliance Flexibility Under $\S 111$ of the Clean Air Act
}

\author{
Gregory Wannier \\ author1769093@ssrn.com \\ Jason A. Schwartz \\ New York University School of Law, jaschwartz@gmail.com \\ Nathan D. Richardson \\ University of South Carolina School of Law, richardson@rff.org \\ Michael A. Livermore \\ University of Virginia School of Law, mlivermore@virginia.edu \\ Michael B. Gerrard \\ Columbia Law School, michael.gerrard@law.columbia.edu
}

See next page for additional authors

Follow this and additional works at: https://scholarship.law.columbia.edu/faculty_scholarship

Part of the Environmental Law Commons

\section{Recommended Citation}

Gregory Wannier, Jason A. Schwartz, Nathan D. Richardson, Michael A. Livermore, Michael B. Gerrard \& Dallas Burtraw, Prevailing Academic View on Compliance Flexibility Under $\S 111$ of the Clean Air Act, RESOURCES FOR THE FUtURE DiscusSiOn PAPER No. 11-29 (2011).

Available at: https://scholarship.law.columbia.edu/faculty_scholarship/1718

This Working Paper is brought to you for free and open access by the Faculty Publications at Scholarship Archive. It has been accepted for inclusion in Faculty Scholarship by an authorized administrator of Scholarship Archive. For more information, please contact scholarshiparchive@law.columbia.edu. 


\section{Authors}

Gregory Wannier, Jason A. Schwartz, Nathan D. Richardson, Michael A. Livermore, Michael B. Gerrard, and Dallas Burtraw 


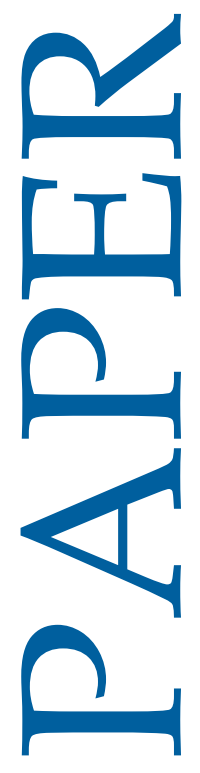

July 2011 RFF DP 11-29

\section{Prevailing Academic View on Compliance Flexibility under $\S 111$ of the Clean Air Act} Gregory E. Wannier, Jason A. Schwartz, Nathan Richardson, Michael A. Livermore, Michael B. Gerrard, and Dallas Burtraw

1616 P St. NW

Washington, DC 20036

202-328-5000 www.rff.org

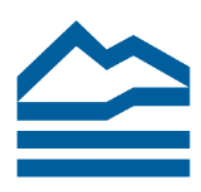

RESOURCES FOR THE FUTURE 


\title{
Prevailing Academic View on Compliance Flexibility under $§ 111$ of the Clean Air Act
}

\author{
Gregory E. Wannier, Jason A. Schwartz, Nathan Richardson, Michael A. Livermore, \\ Michael B. Gerrard, and Dallas Burtraw
}

\begin{abstract}
EPA will soon propose performance standards under Section 111 of the Clean Air Act for greenhouse gas pollution from the two largest emitting stationary source sectors-fossil-fueled power plants and petroleum refineries. The form these standards will take remains unclear. A key issue that will shape the effectiveness of the regulations is the degree to which they enable regulated entities to use flexible approaches to achieve the standards. This discussion paper provides the content of a letter to EPA Administrator Jackson that describes areas of general academic agreement on the EPA's authority to use compliance flexibility options under Section 111 of the Clean Air Act in the development of performance standards for greenhouse gas emissions.
\end{abstract}

Key Words: source category, existing sources, state implementation plan, new sources, tradable performance standards

JEL Classification Numbers: K32, Q54, Q58

(C) 2011 Resources for the Future. All rights reserved. No portion of this paper may be reproduced without permission of the authors.

Discussion papers are research materials circulated by their authors for purposes of information and discussion. They have not necessarily undergone formal peer review. 


\section{Contents}

Executive Summary ..................................................................................................................................... 1

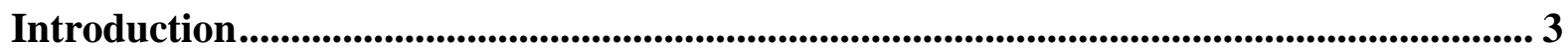

FINDING 1: EPA and states can likely grant compliance flexibility to

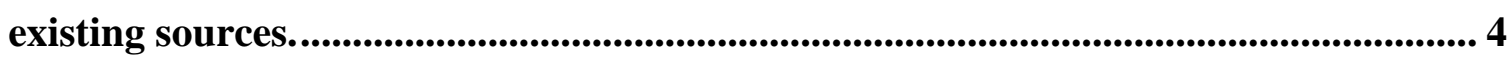

A. Fundamental Justifications for a Flexible System ………………………………….... 4

B. EPA Guidance and Approval of SIP-like State Programs .......................................... 5

C. Potential Conflict with NAAQS ............................................................................... 6

FINDING 2: Compliance flexibility may be possible for new sources, albeit

limited in practice. ...................................................................................................................... 6

A. Fundamental Justifications for a Flexible System ………………………………….... 6

B. Potential Interactions with New Source Review ....................................................... 7

FINDING 3: Inter-sector trading is probably permissible........................................................ 8

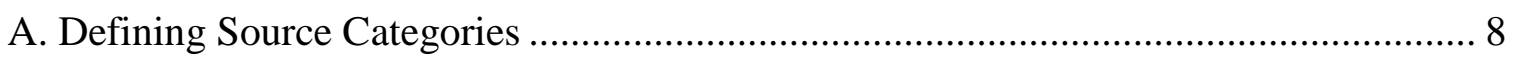

B. Trading Between Source Categories ..................................................................... 8

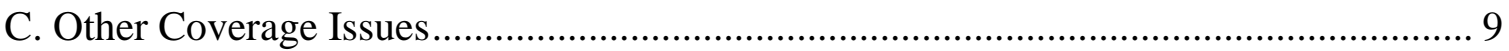

FINDING 4: No consensus exists on whether offsets are permissible. .................................. 9

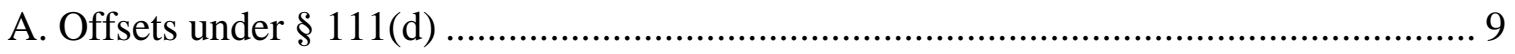

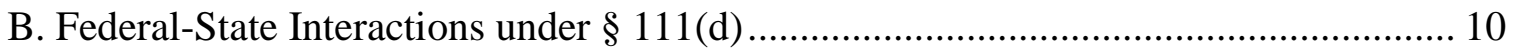

FINDING 5: States have broad allocation authority; EPA's powers are less clear.

Banking and price floors are likely permissible; borrowing and price ceilings are more uncertain. ................................................................................................................................. 10

A. General Allocation Authority.............................................................................. 11

B. Banking and Borrowing .................................................................................... 11

C. Cost-Containment Mechanisms ............................................................................... 11

FINDING 6: Pre-planned changes in the breadth and stringency of standards over time is likely permissible. ............................................................................................................... 12

Conclusion .............................................................................................................................................. 13

Notes ............................................................................................................................................................. 15 


\title{
Prevailing Academic View on Compliance Flexibility under $§ 111$ of the Clean Air Act
}

\author{
Gregory E. Wannier, Jason A. Schwartz, Nathan Richardson, Michael A. Livermore, \\ Michael B. Gerrard, and Dallas Burtraw*
}

\section{Executive Summary}

EPA will soon propose performance standards under Section 111 of the Clean Air Act for greenhouse gas pollution from the two largest emitting sectors-fossil-fueled power plants and petroleum refineries. The form these standards will take remains unclear. Many from industry, environmental groups, and academia argue that to be effective and efficient, the standards should incorporate compliance flexibility. This broad term encompasses a range of design choices that provide spatial or temporal flexibility in achieving aggregate emissions outcomes.

There is widespread agreement in the academic community that $\S 111$ authorizes the use of many types of flexible approaches. Given agency discretion to define uncertain statutory terms like "best system of emission reduction," and given the potential of compliance flexibility mechanisms to reduce costs while preserving total emissions reduction goals, EPA and the states should be able to fit a variety of flexible approaches into the statutory criteria for performance standards.

EPA and states can likely grant compliance flexibility to existing sources. EPA can outline specific flexible structures in its guidance to states, though it likely cannot reject state implementation plans solely for failure to adopt a flexible approach.

Compliance flexibility may be possible for new sources, albeit limited in practice. The plain statutory text supports flexibility for new sources, though a lack of precedent and possible interactions with New Source Review could complicate application.

Inter-sector trading is probably permissible. EPA has broad statutory authority to define the scope of categories of regulated polluters. EPA can likely define a category

\footnotetext{
* Gregory E. Wannier, Deputy Director, Center for Climate Change Law, Columbia Law School; Jason A. Schwartz, Legal Director, Institute for Policy Integrity, New York University School of Law; Nathan Richardson, Resident Scholar, Resources for the Future; Michael A. Livermore, Adjunct Professor, New York University School of Law and Executive Director, Institute for Policy Integrity at New York University School of Law; Michael B. Gerrard, Director, Center for Climate Change Law, Columbia Law School; and Dallas Burtraw, Senior Fellow and Darius Gaskin Chair, Resources for the Future.
} 
encompassing multiple types of major greenhouse gas emitters, and thereby allow trading between sources currently in different categories. Alternatively, even without newly defined or larger categories, there is no express statutory preclusion to trading across existing categories.

No consensus exists on whether offsets are permissible. But even if offsets are not compatible with performance standards, states have broad authority to use offsets for additional emissions reductions.

Banking and price floors are likely permissible; borrowing and price ceilings are more uncertain. States likely have broad powers to assign compliance responsibilities among sources, including the allocation of allowances within a trading program. Whether EPA's powers are as broad is unclear.

Pre-planned changes in the breadth and stringency of standards over time are likely permissible. Both EPA and the states can likely identify a schedule of incremental steps over time to implement additional emissions reductions and lower costs.

\begin{tabular}{|l|l|}
\hline Compliance Flexibility Tool & Legal under CAA? \\
\hline General compliance flexibility (existing sources) & Probably \\
\hline General compliance flexibility (new sources) & No consensus* \\
\hline EPA rejection of state plans granting more/less flexibility & Probably not \\
\hline Inter-sector trading & Probably \\
\hline Offsets & No consensus \\
\hline Banking & Probably \\
\hline Borrowing & No consensus \\
\hline Price floors & Probably \\
\hline Price ceilings & No consensus \\
\hline Declining caps/increasing stringency & Probably \\
\hline State programs that exceed EPA-mandated stringency & Probably \\
\hline State use of tools unavailable under CAA & Probably** \\
\hline Discretionary allocation/auction authority (states) & Probably \\
\hline Discretionary allocation/auction authority (EPA) & No consensus \\
\hline
\end{tabular}

*Even if permissible, New Source Review may be a practical barrier.

**But sources likely cannot use these tools to comply with CAA requirements. 


\section{Introduction}

EPA will soon propose performance standards under Section 111 of the Clean Air Act (CAA) for greenhouse gas (GHG) pollution from the two largest emitting sectors-fossil-fueled power plants and petroleum refineries. These standards will apply to both new sources and, via $\S 111(\mathrm{~d})$ and the states, existing sources - they will be the first federal GHG regulations on these sources.

The form these standards will take remains unclear. Many from industry, environmental groups, and academia argue that to be effective and efficient, the standards should incorporate compliance flexibility. ${ }^{1}$ This broad term encompasses a range of design choices that provide spatial or temporal flexibility in achieving aggregate emissions outcomes. The array of policy options includes tradable rate-based performance standards, bubbles over commonly owned facilities, trading between plant-specific lifetime emissions budgets, and nationwide emissions budgets with market-based exchange, with banking and borrowing - all of which feature the common characteristic of lowering costs without sacrificing ultimate emissions goals.

\section{Overview of Statutory Structure}

Section 111 of the CAA governs EPA's powers to set performance standards for "source categories" (sectors) defined by the agency. First, the agency must list categories of stationary sources that contribute significantly to air pollution that endangers public health or welfare. ${ }^{2}$ Once a category has been defined, EPA must propose a federal standard of performance to regulate all new sources within that category. ${ }^{3}$ These standards must reflect emissions cuts achievable under "the best system of emission reduction which ... the administrator determines has been adequately demonstrated," taking into account costs and other factors. ${ }^{4}$

For pollution regulated elsewhere under the CAA, the $\S 111$ process ends here. But if emissions from existing sources are not controlled via other CAA regulation (and so far for GHG emissions, they are not), § 111(d) of the CAA authorizes EPA to regulate them with performance standards. ${ }^{5}$ EPA sets guidelines for these standards, but the states implement them. This process is explicitly similar to that found in $\S 110$ of the $\mathrm{CAA}^{6}$ and requires states to submit a plan establishing a "standard of performance for any existing source for any air pollutant."7 States have broad flexibility to implement $\S 111(\mathrm{~d})$ standards, ${ }^{8}$ though EPA retains approval power and the ability to regulate if a state fails to do so. ${ }^{9}$ The only explicit limitations on state authority are the requirement that they establish "performance standards" and the EPA regulations requiring that plans be at least as stringent as, and occur at least as quickly as, the federal guidelines, creating a federal emissions backstop. ${ }^{10}$ 
This document addresses whether the CAA, and specifically $\S 111$, allows EPA to use these tools. Generally the relevant legal questions have not yet been directly answered by the courts. ${ }^{11}$ Nevertheless, there is widespread agreement in the academic community that $\S 111$ does authorize the use of many types of flexible approaches. This document explores some areas of potential confusion surrounding flexibility and $\S 111$. Where the prevailing academic view is identified, the findings presented reflect general agreement in the academic community and the unanimous position of the authors.

\section{FINDING 1: EPA and states can likely grant compliance flexibility to existing sources.}

Compliance flexibility (as defined above) for existing sources is almost certainly available to state authorities. EPA can outline specific flexible structures in its guidance to states, though it likely cannot reject state implementation plans solely for failure to adopt a flexible approach.

\section{A. Fundamental Justifications for a Flexible System}

Section 111 of the CAA allows for a high degree of flexibility in implementing standards of performance. As defined under $\S 111$, a standard of performance is based on "the best system of emission reduction ... taking into account the cost." This language almost certainly is broad enough to enable both EPA and states to incorporate compliance flexibility: using their statutory discretion, those authorities can define many flexible approaches as the most efficient (and therefore the "best") systems for reducing emissions at the sector level. ${ }^{12}$ This discretion to define statutory criteria is central to EPA and states' ability to implement any flexibility mechanisms.

The minority opposing view holds that flexible mechanisms cannot be justified, based on an assumed negative inference from statutory silence on specific flexibility mechanisms. A further objection claims that $\S 111$ requires regulation of individual sources, implying no single source can be allowed to emit more and then pay for it. ${ }^{13}$ However, particularly given the deference owed to agencies under Chevron $v . N R D C,{ }^{14}$ such a negative inference is unwarranted. Courts do not typically act on negative inferences without clear congressional intent. ${ }^{15}$ Furthermore, to the extent that Congress has spoken on the issue, it has removed, rather than added, barriers to flexible mechanisms in EPA regulations. In 1990, Congress amended $\S 111$ to remove the word "technology" from its definition of performance standards, indicating that standards need not be technology-based. ${ }^{16}$ 
The legality of flexibility for existing sources under $\S 111$ also has support from past EPA actions. EPA explicitly agreed with, and defended, this interpretation in its 2005 Clean Air Mercury Rule (CAMR). ${ }^{17}$ It is true that EPA's interpretation does not have a long history; as recently as 1998, EPA believed that "trading across plant boundaries is impermissible under sections 111 and 112." "18 However, agencies have generally been granted deference in their evolving interpretation of statutes. ${ }^{19}$

Moreover, states may have some augmented authority to use compliance flexibility for existing sources. Section 111(d) gives states extra authority to consider "other factors" when regulating existing sources. Additionally, the $\S 111(\mathrm{~d})$ procedure explicitly mimics the $\S 110$ process, which grants states great leeway in designing State Implementation Plan equivalents (SIPe) — and which specifically mentions the use of "economic incentives such as . . marketable permits, and auctions of emissions rights."20

\section{B. EPA Guidance and Approval of SIP-like State Programs}

EPA has the authority to outline flexible structures in its guidance to states on existing source regulation, either in the form of a specific preferred option or by listing several alternative options. $^{21}$ EPA almost certainly also has the authority to implement flexible systems in any Federal Implementation Plan equivalent (FIPe), because the CAA gives EPA the identical authority as states in the design of a federal "backstop" program for existing sources. ${ }^{22}$ In fact, if EPA includes some of these flexible mechanisms in its proposed FIPe, it may reduce some of the uncertainty around the question of state equivalency (which is measured against a federal backstop that the FIPe helps to set).

There has been little scholarship on whether states will be able to submit a joint or coordinated SIPe, which would allow trading between states and might be useful in meshing CAA standards with existing regional trading programs (like RGGI). However, neither is there any explicit statutory bar. A limitation on joint SIPes might arise if EPA interprets the statute to require each individual state to develop equivalency with the federal standards. In such a scenario, states buying allowances from other states might fail to reduce their own emissions sufficiently. A negative inference against joint bids may also arise from the fact that other sections of the CAA do explicitly allow for state coordination. However, nothing in the statute requires that EPA mandate state compliance on an individualized basis, ${ }^{23}$ and so states can likely assert this flexibility. 
States retain substantial discretion under the CAA to design their own SIPes for existing sources. ${ }^{24}$ EPA probably lacks the ability to disapprove a given SIPe simply for failing to include flexibility mechanisms that EPA might prefer. States otherwise achieving sufficient reductions cannot be forced to implement any specific flexible system. Nor, conversely, could EPA disapprove a SIPe that includes flexibility that the model rule does not, so long as the flexibility mechanisms are allowable under the CAA.

State efforts to implement reductions through other techniques, including renewable portfolio standards (RPSs), demand-side management, utility planning, and other indirect emission reduction systems, might also qualify for SIPe treatment to the extent that they achieve equivalent emissions reductions and satisfy the criteria of "performance standards." EPA has issued guidance that would allow states to claim credit for emissions reductions of criteria pollutants (like ozone) achieved through adopting energy efficiency and RPS measures under their $\S 110$ SIPs. ${ }^{25}$ Because $\S 111(\mathrm{~d})$ allows states to consider "other factors" and makes explicit reference to following a $\S 110$ SIP-like process, it is possible that states could similarly receive credit for RPSs and energy efficiency efforts under $\S 111 .^{26}$

\section{Potential Conflict with NAAQS}

There is no legal certainty on whether EPA can be forced to adopt National Ambient Air Quality Standards (NAAQS) for greenhouse gases. This is a complex question outside the scope of this document. ${ }^{27}$ However, if EPA were forced to adopt a GHG NAAQS (or chose to do so), regulation of existing sources under $\S 111(\mathrm{~d})$ would be prohibited. ${ }^{28}$ It is worth noting that the legal path to forcing EPA to issue NAAQS would be a very long one: even if this potential conflict does eventually become a problem, a §111-based program could operate successfully for many years.

\section{FINDING 2: Compliance flexibility may be possible for new sources, albeit limited in practice.}

The plain statutory text supports flexibility for new sources, though a lack of precedent and possible interactions with New Source Review could complicate application.

\section{A. Fundamental Justifications for a Flexible System}

Unlike states' authority over existing sources under $\S 111(\mathrm{~d})$, Congress did not grant EPA leeway to consider "other factors" or use SIP-like mechanisms to regulate new sources under $\S$ 111(b). ${ }^{29}$ EPA's ability to use flexible mechanisms therefore turns entirely on whether such 
approaches fit the definition of "performance standard." As explored above, flexible mechanisms can satisfy all the criteria of a performance standard under the plain statutory text. ${ }^{30}$

Nevertheless, the application of flexible approaches to new sources is legally and practically more uncertain than for existing sources. The negative inference argument is plausibly stronger for new sources, given legislative history that continued to link new source standards to technology-specific controls even after the 1990 Amendments. ${ }^{31}$ The regulatory precedent is also weaker: though EPA did include new sources in the market created by CAMR, that rule also simultaneously bound new sources to baseline performance standards. ${ }^{32}$ Finally, some argue that a D.C. Circuit Court of Appeals decision, ASARCO v. EPA, disallowed trading under $\S 111(\mathrm{~b})$, although EPA and others believe the subsequent Supreme Court case Chevron $v$. $N R D C$ invalidated ASARCO. We further note that the statute has been amended since both those cases and the original decision concerned the definition of "source" rather than "performance standard"33 - ASARCO's holding apparently would not apply to an EPA definition of compliance flexibility as "the best system of emission reduction."

Ultimately, courts typically only accept negative inferences if they are confident that Congress intended to preclude the unmentioned policy option. ${ }^{34}$ Additionally, agencies are generally granted deference in their evolving interpretation of statutes, ${ }^{35}$ and EPA will be afforded some discretion to interpret the statutory criteria for "performance standards" under $\S$ 111(b). ${ }^{36}$ Thus, flexible mechanisms are likely available for new sources, ${ }^{37}$ though they remain a risky option because they are untested. ${ }^{38}$ A safer option might be for EPA to issue baseline performance standards for new sources (as it did in CAMR) and, in a separate and severable rulemaking, incorporate new sources under a single flexible regime with existing sources.

Note that any limitations on EPA's authority to regulate new sources under $\S 111(\mathrm{~b})$ either due to negative inferences or legal precedents — will not affect its more expansive authority to regulate existing sources with a $\S 111(\mathrm{~d})$ FIPe in lieu of adequate state action.

\section{B. Potential Interactions with New Source Review}

New sources are also subject to permit requirements under a different CAA program: new source review (NSR). Traditionally, performance standards are less stringent than NSR's "best available control technology" (BACT) requirements. ${ }^{39}$ As the flexibility created under $\S$ 111 incentivizes new sources to adopt tighter emissions controls, emerging technologies may become "available" for purposes of BACT determinations and ratchet up NSR requirements even 
further. EPA will likely need to provide guidance on the interaction between $§ 111$ performance standards and NSR, particularly if flexibility for new sources is explored.

\section{FINDING 3: Inter-sector trading is probably permissible.}

EPA has broad statutory authority to define the scope of categories of regulated polluters. EPA can likely define a category encompassing multiple types of major greenhouse gas emitters, and thereby allow trading between sources currently in different categories. Alternatively, even without newly defined or larger categories, there is no express statutory preclusion to trading across existing categories.

\section{A. Defining Source Categories}

EPA has broad authority to "distinguish among classes, types, and sizes within categories of new sources." 40 Courts have found EPA has "considerable discretion under section 111 " and have upheld EPA's decision to issue a single, uniform standard for sources that were previously treated as separate subcategories. ${ }^{41}$ Thus, EPA can likely expand any existing category to include sources from any other existing category or newly regulated source types (though the latter would also require a new endangerment finding). EPA could even plausibly create a single category for all sources with GHG emissions above a certain threshold. While EPA should be able to exercise this authority to recategorize at any time, it could be more complicated legally or practically for EPA to adjust categories in the future after performance standards already exist. Though EPA is only contemplating GHG performance standards for one or two categories initially, if the agency wants to pursue this option of combining multiple categories in the future, it may want to start soliciting comments now.

\section{B. Trading Between Source Categories}

There is no express statutory preclusion to trading across existing categories. In fact, a flexible mechanism that allows trading across categories could arguably fit the definition of "the best system of emission reduction." $" 42$ Nevertheless, several academics worry that the lack of clear statutory authority or precedent creates some doubt, particularly on the question of whether state equivalency must be demonstrated independently in every regulated category. ${ }^{43}$ The existence of such doubts may suggest that the recategorization method discussed above is the least risky path to inter-sector trading. In any case, states with emissions limits more stringent than EPA's could allow inter-category trading to meet emissions goals beyond EPA's. EPA will likely need to provide guidance on how states will establish equivalency. 


\section{Other Coverage Issues}

A few other legal issues relating to flexibility and scope of coverage are worth mentioning. As with EPA's $\S 202$ endangerment finding, the agency should be able to define the targeted pollutant under $§ 111$ as the mix of all GHGs; ${ }^{44}$ therefore, trading among GHGs should not present any legal problems. Trading between states is also plausibly permissible; though the D.C. Circuit recently limited interstate trading of other pollutants in North Carolina v. EPA, that decision was based on language in $\S 110$ that does not apply to $\S 111$ regulation. ${ }^{45}$

However, there are some limitations on the scope of potential flexibility programs under $\S 111$. For example, the categories of sources covered by $\S 111$ only include "buildings, structures, facilities, or installations which emit or may emit any air pollutant." ${ }^{, 46}$ Since upstream sources of GHGs, like natural gas importers, do not directly emit the pollution generated when a consumer burns the natural gas it processed or sold, these indirect emissions likely cannot be covered under $\S 111$.

\section{FINDING 4: No consensus exists on whether offsets are permissible.}

Consensus is lacking on whether offsets are compatible with $\S 111$ performance standards. Even if not, states have broad authority to use offsets for additional emissions reductions.

\section{A. Offsets under $\S 111(d)$}

As noted above, the prevailing view among legal scholars is that EPA, states operating under $§ 111(\mathrm{~d})$ regulations, and states operating independently can permit trading among sources covered by regulation. This general agreement breaks down somewhat when considering whether emissions reduction measures taken outside the regulated sphere can be included within trading programs. The most prominent such measures are offsets.

Analysts taking the position that offsets are permissible point to elements of legislative history, like the statute's move away from requirements for on-site, technology-based compliance and congressional references to allowable reductions achieved by third parties; $;{ }^{47}$ to the lack of statutory preclusion; ${ }^{48}$ and to the explicit availability of a limited class of offsets under NAAQS. ${ }^{49}$ Other proponents argue that it is difficult to draw principled distinctions between inter-sector trading (see Finding \#3 above) and offsets. ${ }^{50}$

Those taking the opposite position argue that the availability of NAAQS offsets generates a negative inference, ${ }^{51}$ or that offsets appear incompatible with the source category-driven design 
of $\S 111 .^{52}$ Section 111 performance standards, unlike NAAQS, explicitly target emissions reductions from regulated source categories, rather than concentrations of a regulated pollutant. ${ }^{53}$ Offset critics argue that this may pose a modest problem for offsets created by reducing emissions at unregulated facilities, since they do not reduce emissions from any regulated source category. They further suggest that it poses more serious problems for offsets that have no effect on emissions, but putatively affect ambient greenhouse gas concentrations (such as forest offsets). ${ }^{54}$

\section{B. Federal-State Interactions under $\S 111(d)$}

There appear to be few limits on states' ability to incorporate offsets into their independent state and regional-level programs, such as AB32 and RGGI. ${ }^{55}$ If states are able to use offsets (or other alternative compliance mechanisms) in their independent programs, but not under $\S 111(\mathrm{~d})$, the relationship between the CAA and state/regional programs becomes more complex. To the extent that emitters use offsets or other tools to comply with state program requirements, EPA and the states may be unable to count those reductions for purposes of compliance with $\S 111(\mathrm{~d})$ regulations. This is not necessarily fatal to efforts to achieve compatibility: the CAA does not preempt state programs, which would presumably be more stringent. Offsets and related tools could still be used to meet this additional compliance burden.

It is not clear whether a state could implement more stringent regulation, perhaps including offsets, via its SIPe (relying on CAA authority) ${ }^{56}$ or if separate supporting state legislation would be required. Constitutional limits on state power (for example, the requirement for congressional approval of inter-state compacts, ${ }^{57}$ or the inability of states to engage in binding international agreements ${ }^{58}$ ) may also limit certain types of offset arrangements.

\section{FINDING 5: States have broad allocation authority; EPA's powers are less clear. Banking and price floors are likely permissible; borrowing and price ceilings are more uncertain.}

States likely have broad powers to assign compliance responsibilities among sources, including the allocation of allowances within a trading program. Whether EPA's powers are as broad is unclear. Banking and price floors are likely permissible, though there is no consensus on borrowing or price ceilings. 


\section{A. General Allocation Authority}

States almost certainly have the authority to allocate permits however they choose, provided minimum federal emissions standards are still met. ${ }^{59}$ For example, states could conduct a coordinated auction or distribute permits in a manner that promotes policy goals, such as protecting consumers by allocating based on output in order to lessen electricity price changes and preserve in-state generation, or rewarding individual facilities for repowering and/or biomass use. ${ }^{60}$ EPA can also allocate permits in many different ways. There is no consensus on whether EPA can auction permits, ${ }^{61}$ but if it can, any revenue would need to go directly to the treasury. ${ }^{62}$

\section{B. Banking and Borrowing}

Several existing market-based approaches to flexible compliance include banking and borrowing mechanisms, whereby excess reductions can be saved for future compliance periods or facilities with insufficient reductions can pay extra in future compliance periods. Unlimited banking would probably not compromise state equivalency requirements, because emissions reductions need only be realized at least as quickly as the federal standard. ${ }^{63}$

Borrowing against future compliance periods is more legally ambiguous, since it could violate the requirement that a SIPe achieve reductions at least as quickly as the EPA backstop would. Some scholars have pointed to $§ 110(a)(2)(A)$, which allows SIPs to include schedules and timetables for compliance, as granting states some independence on the timeline for compliance from federal norms (recall that § 111(d) references the § 110 SIP-approval process). ${ }^{64}$ Further, the ability of states to account for "other factors" under $\S 111(\mathrm{~d})$ may imply that states can consider future compliance promises in allowing more immediate deviations from EPA baselines. However, there is no academic consensus on whether such language in fact justifies borrowing. The strongest language against borrowing comes in EPA's own requirements that state plans achieve emission reductions "at least as quickly" as the federal baseline ${ }^{65}$ though this requirement is not explicitly mandated by the statutory text, and EPA could change this regulation in the context of GHGs in order to more clearly permit some borrowing mechanisms.

\section{Cost-Containment Mechanisms}

Another common feature of emissions markets is a floor and ceiling price beyond which no allowances can be sold. A floor price does not present any complications, because if it has any effect, it will be to reduce emissions. However, a ceiling price on allowances enforced with an unlimited ability to buy allowances at a given maximum price could (similar to offsets, above) 
cause a SIPe to fail the equivalency requirement. A ceiling price that works by borrowing future allowances might be permissible if borrowing itself is allowed.

The ability of states to consider cost and other factors in setting up their emissions reduction systems under $\S 111(\mathrm{~d})$ may independently allow for controls on allowance prices. ${ }^{66}$ EPA may be able to reduce some of the uncertainty around the question of state equivalency and price ceilings if it uses its own statutory authority to apply reasonable cost constraints to its FIPe and emissions standards. ${ }^{67}$ States could then likely set a price ceiling at or above EPA's own determination of reasonable costs.

\section{FINDING 6: Pre-planned changes in the breadth and stringency of standards over time is likely permissible.}

Both EPA and the states can likely identify a schedule of incremental steps over time to implement additional emissions reductions and lower costs.

The text and structure of $\S 111$ likely authorize rulemakings that both set an initial emissions reduction target and establish a schedule for incremental steps over time to implement additional reductions. It is possible that $\S 111(\mathrm{~b})(1)(\mathrm{B})$ 's description of a specific process for the review and revision of performance standards creates a negative inference against a prospective timetable of automatically increasing requirements. However, the eight-year review process could apply as easily to prospective timetables; the provision requires retrospective analysis regardless of the rule's form, but it does not bind EPA's hands on policy design choices.

The real question is whether an automatic timetable could fit the definition of a "performance standard." Performance standards must reflect the degree of emissions limitations achievable through application of the best system adequately demonstrated. However, at least as applied to new sources, the courts have found that $\S 111$ "looks toward what may fairly be projected for the regulated future, rather than the state of the art at present." ${ }^{, 68}$ Neither "adequately demonstrated" nor "achievable" means that the standard is limited to what can already be routinely achieved. ${ }^{69}$ While EPA cannot base standards on pure theory or speculation, it can make reasonable extrapolations of technological performance. ${ }^{70}$ This understanding of the definition of "performance standard" could support a rule that prospectively sets a schedule of incremental steps.

EPA's mandate to consider costs ${ }^{71}$ could also support such an interpretation of its authority. Implementation costs will be affected by the implementation schedule. A timetable allows the agency to gradually increase the emissions limitations in line with cost-sensitive 
predictions about the rate of technological development. If the agency instead were forced to set a single standard meant to govern for the foreseeable future, that standard would likely be initially more stringent and, therefore, more costly.

States should also have the ability to establish a series of incremental steps under $\S$ 111(d). As described above, ${ }^{72}$ states are given two sources of additional authority under $\S 111(\mathrm{~d})$. First, the section references the procedures under $\S 110$; section 110 specifically notes the states' ability to set "schedules and timetables for compliance."73 Second, $§ 111(\mathrm{~d})$ instructs states to consider other relevant factors, including the remaining useful life of existing sources. One way to account for the remaining lifetimes of plants might be to establish a timetable of gradually increasing stringency.

Even if EPA or the states choose not to exercise this authority to adopt mandatory timetables with incremental steps, they can still include non-binding language in the rule or the preamble signaling future intent to increase stringency, redefine categories, or make other changes. If the agency does ultimately make substantive changes to its policies pursuant to such signaling statements, new rulemakings would be required. But in the meantime, such signals can be helpful in aligning expectations and investments in the regulated community, even though such signaling statements are not likely binding on the agency. Moreover, either the signaling of intent or enactment of a series of incremental steps could be relevant to the ability of the United States to make commitments in international negotiations.

\section{Conclusion}

There is agreement — broad among legal academics and universal among the authors here- that EPA has the tools under $\S 111$ of the CAA to implement relatively flexible and efficient GHG regulation. The agency could use a range of compliance flexibility options itself, or facilitate state implementation plans that adopt such measures at the state or regional level.

EPA appears to have authority to include many specific flexible or market-design tools in $\S 111$ regulation, including tradable performance standards operating across sectors, price floors, banking of credits or allowances, and, in principle, nationwide cap-and-trade. Regulations likely can also increase in breadth or stringency over time-EPA appears to have the authority (and the opportunity) to achieve ambitious environmental goals while providing regulatory predictability to industry. These tools can make CAA policy more effective and more efficient. More broadly, EPA can — indeed must — consider both costs and other environmental impacts in setting GHG performance standards. 
Authority under $\S 111$ is not unlimited and at times not clear, however. For instance, it is unclear whether EPA can grant full compliance flexibility to new sources. Moreover, even for existing sources it is unclear what powers EPA would have to allocate any allowances, and whether the use of offsets, borrowing, or price ceilings by either the states or EPA would be compatible with $\S 111$ standards. Courts (or Congress) may ultimately resolve these ambiguities - though litigation is likely even if EPA is cautious.

States are key to the CAA pathway. The statute allows and requires substantial participation by the states, which retain significant control over the degree of compliance flexibility allowed for in-state emitters regardless of EPA's position. If their chosen system involves emissions allowances, states can likely allocate them as they see fit. States can also regulate more stringently than EPA if they wish — $\$ 111$ regulation does not preempt existing state emissions programs like RGGI and AB32. Tools unavailable to EPA likely remain available to the states in their presumably more stringent programs, though states that use such tools may be forced to choose between subjecting emitters to dual requirements or allowing their use only for the additional local compliance burden.

The above uncertainty should not, however, distract from the larger conclusion that EPA has much of the authority it needs. To forgo compliance flexibility would be excessively cautious; arguably, carefully designed compliance flexibility is required for the agency to meet its statutory requirement to implement the best system of emissions reductions. 


\section{Notes}

${ }^{1}$ For example, see Coalition for Emission Reduction Policy, Comments on EPA's Forthcoming Proposal to Establish New Source Performance Standards for GHG Emissions from Electric Generating Units and Refineries, Mar. 18, 2011 (support for compliance flexibility from industry groups); Franz T. Litz, Nicholas M. Bianco, Michael B. Gerrard, \& Gregory E. Wannier, World Resources Institute \& Columbia Law School Center for Climate Change Law, What's Ahead for Power Plants and Industry? Using the Clean Air Act to Reduce Greenhouse Gas Emissions, Building on Existing Regional Program (World Resources Institute Working Paper, 2011) (support from an environmental group and an academic center).

2 Clean Air Act $§ 111(b)(1)(A), 42$ U.S.C. $§ 7411$ (2010) [hereinafter CAA].

${ }^{3}$ CAA $\S 111(b)(1)(B)$.

${ }^{4}$ CAA $\S 111(\mathrm{a})(1)$. States also have an important role here: under $\S 111(\mathrm{c})$, they are free to propose plans to implement and enforce the new source standards created by EPA.

5 Specifically, if existing sources are not already covered by national ambient air quality standards under $\S 110$ or hazardous air pollutant standards under $\S 112$, then $\S 111(\mathrm{~d})$ is triggered.

6 This section governs the National Ambient Air Quality Standards (NAAQS), under which “conventional” pollutants such as $\mathrm{NO}_{\mathrm{x}}, \mathrm{SO}_{2}$, lead, ozone, and particulates are regulated.

${ }^{7}$ CAA $\S 111(d)$. Note that the same $\S 111($ a) definition of “standard of performance" applies to states' $\S 111(d)$ regulation.

8 States are guided in part by $\S 111$ (d)(1)'s reference to $\S 110$ 's State Implementation Plan process, notably including $\S 110(\mathrm{a})(2)(\mathrm{A})$, which allows states to employ "other control means, measures or techniques (including economic incentives such as fees, marketable permits, and auctions of emissions rights)." States are also permitted by $\S 111(\mathrm{~d})(2)(B)$ to take into account the remaining useful life of an existing source.

${ }^{9}$ See CAA $§ 111(\mathrm{~d})(2)$.

10 Emissions Standards and Compliance Schedules, 40 C.F.R. $§ 60.24$ (c) (2010).

11 Notably, the D.C. Circuit Court of Appeals had the opportunity to rule on whether $\S 111$ allows one form of compliance flexibility (a nationwide cap-and-trade system), during litigation challenging EPA's 2005 Clean Air Mercury Rule. The court did not reach the issue and instead rejected the rule on other, unrelated grounds. See New Jersey v. EPA, 517 F.3d 574 (D.C. Cir. 2008). Recently, in Am. Elec. Power Co. v. Connecticut, No. 10-174 (U.S. June 20, 2011), the Supreme Court discussed that EPA will be using $§ 111$ to regulate GHGs from power plants, but did not explore EPA's authority in depth.

12 See Standards of Performance for New and Existing Stationary Sources: Electric Utility Steam Generating Units (Clean Air Mercury Rule), 70 Fed. Reg. 28,606 (July 18, 2005) (EPA's interpretation of the definitions of "performance standard" under §§ 111 and 302); Inimai M. Chettiar \& Jason A Schwartz, The Road Ahead: EPA's Options and Obligations for Regulating Greenhouse Gases 86-88 (Institute for Policy Integrity Report No. 3, 2009). The statutory mandate to "tak[e] into account the cost" could also be important here. While courts have determined that this language does not require EPA to base its determinations on a formal cost-benefit analysis, they have stated "because Congress did not assign the specific weight the Administrator should accord each of these factors, the Administrator is free to exercise his discretion in this area." New York v. Reilly, 969 F.2d 1147, 1150 (D.C. Cir. 1992).

13 For a description-and refutation - of the alleged negative inference from statutory silence and the structure of $\S 111(\mathrm{~h})$, as well as of the argument that $\S \S 111$ and 302 require emissions reductions from individual sources, see Chettiar \& Schwartz, supra note 12, at 87-89.

14 Chevron U.S.A. v. Natural Res. Def. Council, Inc., 467 U.S. 837 (1984).

15 See Texas Rural Legal Aid Inc. v. Legal Serv. Corp., 940 F.2d 685, 694 (D.C. Cir. 1991) (explaining that the expressio unius est exclusion alterius canon "has little force in the administrative setting. Under Chevron, we normally withhold deference from an agency's interpretation of a statute only when Congress has 'directly spoken to the precise question at issue,' and the expressio canon is simply too thin a reed to support the conclusion that Congress has clearly resolved this issue"); Fin. Planning Assoc. v. SEC, 482 F.3d 481 (D.C. Cir. 2007) (noting "this court has repeatedly held that expression unius is 'an especially feeble helper in an administrative setting, where Congress is presumed to have left to reasonable agency discretion questions that it has not 
directly resolved"').

${ }^{16}$ See Jonas Monast et al., Avoiding the Glorious Mess: A Sensible Approach to Climate Change and Clean Air Act (Nicholas Institute for Environmental Policy Solutions Working Paper, Duke University, 2010) (citing EPA's reference to these amendments).

${ }^{17}$ See CAMR, 70 Fed. Reg. 28,606. Note that although CAMR was overturned in the D.C. Circuit Court of Appeals, the grounds for this decision were based on EPA's incorrect delisting of mercury under $\S 112$, and did not address EPA's $\S$ 111 interpretations. New Jersey, 517 F.3d 574. EPA has also permitted states to use trading programs for solid waste combustion performance standards under $\S 129$, a statutory section that shares some common elements and history with $\S 111$ (though $\S 111$ (d) arguably gives states even more flexibility). See EPA, Section 129 Rules for Solid Waste Combustion, http://www.epa.gov/ttn/atw/129/gil2.pdf.

${ }^{18}$ See Memorandum from Jonathan Cannon, EPA General Counsel, to Carol Browner, EPA Administrator, Apr. 10, 1998, available at http://www.law.umaryland.edu/environment/casebook/documents/EPACO2memo1.pdf.

${ }^{19}$ See Nat'l Cable \& Telecomm. Assoc. v. Brand X Internet Services, 545 U.S. 967 (2005).

${ }^{20} \mathrm{CAA} \S 110(\mathrm{a})(2)(\mathrm{A})$.

${ }^{21}$ Such language would not have legal force, and therefore would likely be unreviewable; any limits to EPA's authority to allow innovative systems will instead likely come in its SIPe approval process.

${ }^{22} \mathrm{CAA} \S 111(\mathrm{~d})(2)$ ("The Administrator shall have the same authority").

${ }^{23}$ We do not address the issue here of whether such joint SIPes would be open to challenge on constitutional grounds, such as possible violation of the Compacts Clause.

${ }^{24}$ See Virginia v. EPA, 108 F.3d 1397 (D.C. Cir. 1997); Florida Power \& Light Co. v. Costle, 650 F.2d 579 (5th Cir. 1981); Train v. NRDC, 421 U.S. 60 (1975) ("The Act gives the Agency no authority to question the wisdom of a State's choices of emission limitations if they are part of a plan which satisfies the standards of $\S 110(\mathrm{a})(2)$ )").

25 EPA, Roadmap for Incorporating Energy Efficiency/Renewable Energy Policies and Programs into State Implementation Plans/Tribal Implementation Plans (2011); EPA, Guidance on SIP Credits for Emissions Reductions from Electric-Sector Energy Efficiency and Renewable Energy Measures (2004). This guidance has been applied successfully in Texas, Shreveport, Louisiana, and the D.C. Region, all of which altered their SIPs to receive credit for reductions achieved through energy efficiency and renewable energy efforts. Id.

26 Pew Ctr. on Global Climate Change, GHG New Source Performance Standards for the Power Sector: Options for EPA and the States 10 (2011).

27 For some different perspectives, see Nathan Richardson, Greenhouse Gas Emissions under the Clean Air Act: Does Chevron Set the EPA Free?, 29 STAN. EnV. L. J. 283 (2010) (arguing that courts could interpret the CAA to require EPA to set a NAAQS for GHGs based on its endangerment finding); Nathan Richardson, Dallas Burtraw, and Art Fraas, Resources for the Future, Greenhouse Gas Regulation Under the Clean Air Act: Structure, Effects, and Implications of a Knowable Pathway, 41 ENV. L. NEWS \& ANALYSIS 10098 (2011) (noting EPA will not want to waste resources creating complex regulations under $\S 111$ if they may eventually fail when NAAQS are triggered); Jonas Monast et al., supra note 16 (suggesting that $§ 111$ regulations, if designed right, might be portable into the NAAQS system); and Chettiar \& Schwartz, supra note 12 (discussing whether NAAQS are discretionary and the workability of market-based programs under NAAQS). EPA has been petitioned to adopt NAAQS for greenhouse gases, and the issue may be resolved independently in litigation before the D.C. Circuit Court of Appeals.

28 See CAA $\S 111(\mathrm{~d})(1)(\mathrm{A})$ (limiting $\S 111(\mathrm{~d})$ standards to those pollutants not regulated under $\S \S 110$ or 112 of the Act).

${ }^{29}$ Note that $\S 111$ (c) only allows states to step into EPA's shoes and help regulate new sources; it does not transport their $\S 111(d)$-type authority into the arena of new sources controls.

30 See supra note 12 and accompanying text.

31 See Chettiar \& Schwartz, supra note 12 , at 89.

32 In other words, new sources could exceed minimum emissions reductions and generate tradable credits, but could not enter the program as net buyers of credits. See CAMR, 70 Fed. Reg. 28,606.

33 See Brief for Respondent, New Jersey v. EPA, 517 F.3d 574 (D.C. Cir. 2007) (No. 05-1097). 
34 See supra note 15.

${ }^{35}$ See Nat'l Cable \& Telecomm. Assoc. v. Brand X Internet Services, 545 U.S. 967 (2005).

36 See supra note 14 and accompanying text.

37 Monast et al., supra note 16; Chettiar \& Schwartz, supra note 12.

38 Richardson, Burtraw, \& Fraas, supra note 27; Pew Ctr. on Global Climate Change, supra note 26.

${ }^{39}$ See EPA, Air Quality Management, http://www.epa.gov/apti/course422/apc4d.html (explaining NSPS sets a national baseline, which NSR allows state authorities to apply more stringent controls on a case-by-case basis).

40 See CAA § 111(b)(2).

41 Lignite Energy Council v. EPA, 198 F.3d 930, 933 (D.C. Cir. 1999).

42 Chettiar \& Schwartz, supra note 12.

43 Litz, Bianco, Gerrard, \& Wannier, supra note 1; Richardson, Burtraw, \& Fraas, supra note 27; Pew Ctr., supra note 26.

${ }^{44}$ Cf. Endangerment and Cause or Contribute Findings for Greenhouse Gases under Section 202 of the Clean Air Act, 74 Fed. Reg. 66,496 (Dec. 15, 2009).

45 See North Carolina v. EPA, 531 F.3d 896 (D.C. Cir. 2008); compare CAA § 110(a)(2)(D) with CAA § 111.

${ }^{46}$ CAA $\S 111(\mathrm{a})(3)$.

47 Chettiar \& Schwartz, supra note 12.

48 Id.

49 Coalition for Emission Reduction Policy, supra note 1.

${ }^{50}$ Correspondence with Kyle Danish, Van Ness Feldman P.C. (July 7, 2011).

51 Richardson, Burtraw, \& Fraas, supra note 27.

52 Id.; Litz, Bianco, Gerrard, \& Wannier, supra note 1.

53 See Molly Macauley \& Nathan Richardson, Seeing the Forest and the Trees: Technological and Regulatory Impediments for Global Carbon Monitoring, BERKELEY J. L. \& TECH. (forthcoming 2011).

54 Id.

55 Some scholars have identified potential constitutional issues if states attempt to include international carbon offsets. See Douglas A. Kysar \& Bernadette A. Meyler, Like a Nation State, 55 UCLA L. REV. 1621 (2008); Erwin Chermerinsky et al., California, Climate Change, and Constitution, 37 ELR 10,653 (2007). These could arise under the Compacts Clause or other doctrines restricting states' interference with federal foreign affairs powers. While the outcome of any such constitutional challenges is of course uncertain, many scholars appear to believe that they would be relatively unlikely to succeed. See, e.g., Litz, Bianco, Gerrard, \& Wannier, supra note 1.

56 See Litz, Bianco, Gerrard, \& Wannier, supra note 1.

57 U.S. CONST. Art. I $§ 10$.

58 But see Curtis A. Bradley, The Treaty Power and American Federalism, 97 Mich. L. Rev. 390, 461 (quoting Virginia v. Tennessee, 148 U.S. 503, 519 (1893)).

59 Pew Ctr. on Global Climate Change, supra note 26.

60 Note that while there may some legal limits on the ability of EPA or states to exempt biomass from coverage or apply different performance standards to them, such limitations do not affect states' ability to distribute their permits as they see fit.

61 Compare Richardson, Burtraw, \& Fraas, supra note 27 (rejecting EPA authority to auction permits) with Chetiar \& Schwartz, supra note 12 (supporting EPA authority to auction permits).

62 See Miscellaneous Receipts Act, 31 U.S.C. § 3302 (2010). 
${ }^{63}$ Cf. Publication of Guidance Documents, Emission Guidelines, and Final Compliance Times, 40 C.F.R. § 60.22 (2010).

64 For example, California's RECLAIM program for NOx emissions, implemented under its $§ 110$ SIP, allowed limited borrowing by establishing overlapping compliance periods. See Dallas Burtraw \& Sarah Jo Szambelan, U.S. Emissions Trading Markets for SO2 and NOx, in Permit Trading in Different Applications 29 (Bernd Hansjürgens ed. 2010).

6540 C.F.R. $§ 60.22$.

${ }^{66} \mathrm{CAA} \S 111(\mathrm{~d})$.

67 Under the definition of performance standard, EPA must "tak[e] into account the cost." CAA § 111(a).

68 Portland Cement Ass'n v. Ruckelshaus, 486 F.2d 375, 391 (D.C. Cir. 1973).

${ }^{69}$ Essex Chemical Corp. v. Ruckelshaus, 486 F.2d 427 (D.C. Cir. 1973).

70 Weyerhaeuser Co. v. Costle, 590 F.2d 1011, 1054 n.70 (D.C. Cir. 1978); Essex, 486 F.2d 427.

${ }^{71}$ See supra note 67.

${ }^{72}$ See supra note 20 and accompanying text.

${ }^{73}$ CAA $\S 110(a)(2)(A)$. 